\title{
Representação Social e Formação Continuada dos Professores da Educação Básica da Escola Estadual Manoel Bandeira
}

\author{
Giselle Pupim Jorge Back ${ }^{l}$
}

Resumo: O presente artigo objetiva estudar as representações sociais a luz da formação continuada na Escola Estadual Manoel Bandeira de Alta Floresta, Estado de Mato Grosso, trazendo a reflexão de como essas representações sociais interferem diretamente na construção de nossa identidade profissional. Permitindo essa consideração a respeito dos programas desenvolvidos nas formações continuadas, torna-se relevante para o campo acadêmico educacional. Optou-se por realizar uma pesquisa qualitativa, usando o método dialético através de uma pesquisa participante. As fontes científicas utilizadas para o embasamento teórico desta pesquisa foram livros, revistas e Internet com autores como Falsarella (2004), Freitas (2007), Perrenoud (2000), Nóvoa (1991), Freire (1991), Luckesi (1994), Libâneo (2005), Guareschi (1994), Moscovici (1978) e Jodelet (2002). Os resultados indicam que as representações sociais dos profissionais constituem a identidade da escola e perpassando pela didática de cada um. Também configuramos o grupo sendo predominantemente feminino e autodenominado branco. Os profissionais idealizam a formação docente e continuada como suporte para suas atividades diárias, mas no momento esse tipo de formação não satisfaz essas necessidades reais.

Palavras-chave: Educação, Representação social e Prática Pedagógica.

\section{Social Representation and Basic Education Teacher Training Continued of the Manoel Bandeira State School}

\begin{abstract}
This article aims to study social representations in the light of continuing education at the Manoel Bandeira State School in Alta Floresta, in Mato Grosso, bringing the reflection of how these social representations interfere directly in the construction of our professional identity. Allowing this consideration of programs developed in continuing education, it becomes relevant to the educational academic field. It was decided to carry out a qualitative research, using the dialectic method through a participant research. The scientific sources used for this research were books, magazines and Internet with authors such as Falsarella (2004), Freitas (2007), Perrenoud (2000), Nóvoa (1991), Freire (1991), Luckesi (2005), Guareschi (1994), Moscovici (1978) and Jodelet (2002). The results indicate that the social representations of professionals constitute the identity of the school and pass through the didactics of each one. We also configured the group being predominantly female and self-described white. Professionals idealize teacher and continuing education as support for their daily activities, but at the moment this type of training does not meet these real needs.
\end{abstract}

Keywords: Education, Social Representation, Pedagogical Practice.

\footnotetext{
${ }^{1}$ Mestranda em Educação. Contato: giselle.pupim@gmail.com
} 


\section{Introdução}

As avaliações realizadas em nosso país mostram que precisamos fazer uma reflexão acerca de nossa educação. As crianças entram na escola cada vez mais cedo, mas isso não está fazendo com que os resultados sejam mais animadores. Através dos inúmeros casos de insucesso escolar, muitos estudiosos buscam respostas e alternativas para resolver esse impasse. Como justificativa, fala-se na falta de participação da família e dos insuficientes investimentos financeiros na educação, no entanto, uma questão muito relevante também, é a nossa formação docente.

Nos últimos 20 anos, alguns dos poucos trabalhos que relacionam identidade, prática e cultura docente têm mostrado que os professores estão a espera de mudanças na cultura escolar. É possível perceber através de estudos como os propostos por Seidman, Thomé, Di Lioro e Azzolini (2012) sobre representações sociais, construção identitária e trabalho docente, nos mostrando que essa prática também não está condizendo com a nossa realidade. Passamos alguns anos entre graduação e formações continuadas e infelizmente não conseguimos, na maioria das vezes, relacioná-las com nossas práticas docentes.

\footnotetext{
A reflexão sobre a prática não resolve tudo, a experiência refletida não resolve tudo. São necessárias estratégias, São necessárias estratégias, procedimentos, modos de fazer, além de uma sólida cultura geral, que ajudam a melhor realizar o trabalho e melhorar a capacidade reflexiva sobre o que e como mudar. (LIBÂNEO, 2005, p.76)
}

Nota-se que a cada ano que passa novos discentes são recebidos na escola e, no entanto, continua-se executando métodos embasados em um senso comum, misturados repentinamente com teóricos ou tendências novas virando assim, uma colcha de retalhos com pequenos pedaços de Paulo Freire (1995), Emília Ferreiro (1980), Perrenout (2000), entre tantos.

Programas e Projetos de Formação Continuada para os educadores, como o Programa do Pró-Letramento em Alfabetização, Linguagem e Matemática (MEC/ SEB), o Projeto Gestar (MEC/ SEB), PRALER (MEC/ SEB), ProInfantil (MEC/ SEB), Programa Educação em Direitos Humanos (MEC/ SEDH), investidos pelo Governo Federal, priorizam melhorar a qualidade do ensino e assistir as demandas da sociedade. No entanto, esse objetivo está longe de ser atingido, uma vez que os docentes acabam se envolvendo na rotina diária de sala de aula e preenchimento de papéis, acabando por não fazer uma reflexão acerca de sua práxis pedagógica. 
O avanço tecnológico e a demanda educacional comprovam que necessitamos, urgentemente, de reflexões sobre nossa prática pedagógica afim de que possamos atender aos anseios atuais da sociedade. É impossível pensar em um aluno alheio a essa sociedade visto que a imprescindível relação mútua origina diferentes saberes e culturas. Consequentemente podemos pensar em educação humanizada onde a aprendizagem não se dá somente na sala de aula, mas também na família, religião, trabalho e a comunidade ao qual está inserido.

Como afirma Jean Jacques Rosseau (1959):

Que se destine meu aluno á carreira militar, eclesiástico ou à advocacia, pouco me importa. Antes da vocação dos pais, natureza chama-o para a vida humana. Viver é o ofício que quero ensinar. Saindo de minhas mãos, ele não será, concordo nem magistrado, nem soldado, nem padre; será primeiramente um homem.

Franco eVarlott ressalvam que,

Complementando a prática social estabelecida no contexto escolar é um produto histórico humano que é construído a prática social estabelecida no contexto escolar é um produto histórico da humanidade que é construído ou vai sendo construído pela dinamicidade d linguagem sendo esta "um produto pensado e falado é, portanto, fruto da atividade humana ou seja uma réplica interiorizada da ação. (20014, p.19)

Sendo assim, as representações sociais abordam os processos de produção de sentidos de objetos de interesse da educação, também suas relações com a cultura, suas implicações nas práticas dos agentes educativos e sua contribuição para a construção de identidade. Estas estão necessariamente relacionadas às práticas cotidianas e ás identidades pessoais e culturais.

Conhecer um pouco sobre a forma de pensar e de agir que o corpo docente de uma escola possui, é fundamental para que essa instituição construa seu ideal de formação continuada, bem como compreender as representações sociais que envolvem a escola e a construção de sua identidade. É nesse sentido que este artigo nos trará uma breve reflexão sobre formação continuada e as representações sociais dos professores da Escola Estadual Manoel Bandeira, sendo de relevante para a reflexão da educação e de sua identificação enquanto instituição escolar. Suscitar esse debate é importante para que o professor possa refletir sobre suas práticas pedagógicas.

A escolha desta instituição de ensino se deu pelo motivo de estar inserida nesse campo e ser agente participativo desta pesquisa. Foram selecionados doze professores dessa rede estadual de ensino, que trabalham com alunos de classe média-baixa, na faixa etária de 6 a 14 
anos. A maioria desses docentes leciona na referida unidade escolar há mais de cinco anos e, no entanto, sempre com as mesmas objeções sobre a formação continuada ser sempre repleta de leituras enfadonhas e sem significância para o processo ensino-aprendizagem e a problemática.

\section{Formação Continuada e as Políticas Públicas}

Na década de 1990 a Educação estava centralizada na implantação do Plano Decenal de Educação para Todos (1993), o qual concebe a valorização do docente pela conjugação simultânea de três linhas: a carreira, as condições de trabalho e a qualificação e formação continuada. Logo em seguida são elaboradas várias políticas públicas, tendo como início, a Lei de Diretrizes e Bases da Educação Nacional (LDB N 9394/1996), determinando no artigo 61 o aperfeiçoamento profissional continuado, inclusive em serviço; e definindo no artigo 62, a formação de professores para as séries iniciais e educação infantil em nível superior; e apontando no artigo 67, elementos significativos para a valorização da formação docente.

Com essa preocupação criou-se em 1997 o CEFAPRO (Centro de Formação e Atualização de Profissionais da Educação Básica) no Estado de Mato Grosso. Seu principal foco seria "auxiliar os professores da rede pública de ensino a refletirem sobre a repercussão social de sua prática" (MATO GROSSO, 1998b, p. 3). Surge então um centro de formação específico para formação continuada e formação de profissionais não habilitados. Na época, segundo Mato Grosso (1998) haviam 2.600 professores efetivos atuando nas escolas e que não estavam habilitados.

Nas Orientações Gerais da Rede Nacional de Formação Continuada de Professores (BRASIL, 2005), são descritos todos os princípios e diretrizes norteadores do processo. Assim a SEDUC/CEFAPROs em parceira com o Ministério de Educação tem organizado ações para incentivar a formação continuada no horário de trabalho e em momentos coletivos. Essas também precisam estar alicerçadas aos Projetos Políticos Pedagógicos das escolas. Conforme aponta o documento intitulado "políticas de Formação dos Profissionais da Educação básica de Mato Grosso, objetivando nortear as diretrizes da formação inicial e continuada dos Profissionais da Educação da Rede Estadual, 
[...] envolvimento em estudos contínuos e sistemáticos seja através de programas especialmente organizados pelas instituições de Ensino Superior e/ou Secretarias de Educação, ou aquelas definidas no próprio contexto da unidade escolar. (2010, p.17)

O Projeto de Lei 8035/2010 e o Decreto 6755/2009 formulam o Plano Nacional de Educação de 2001 (PNE) e o atual para uma política nacional voltada para a formação dos profissionais da educação, trazendo-a como fundamental para uma educação de qualidade. Mas, é mediante a elaboração e execução do Programa/Projeto Sala de Professor/Educador que a Formação Continuada assume um caráter específico e se concretiza. É encaminhado para as escolas um projeto modelo elaborado pela SEDUC (MATO GROSSO, 2011) e a partir do mesmo, cada instituição escolar formula seu projeto focando suas necessidades e anseios. O Programa é uma "ação contínua e permanente de estudos entre professores coordenadores pedagógicos, professores docentes, gestores e funcionários no âmbito da escola”; e o principal desafio "consiste no estudo coletivo compartilhado dos profissionais da e, na escola" (MATO GROSSO, 2011b, p. 16).

Por consistir em um estudo coletivo, a Formação Continuada passa a ser um processo crítico-reflexivo que requer uma transformação da realidade, caracterizando então com uma metodologia de pesquisa-ação. Com caráter participativo e democrático visa à construção ou reconstrução da identidade escolar e também profissional.

\section{Breve Histórico das Representações Sociais}

Podemos pensar no coletivo de pessoas de um país, sujeitos à mesma gestão política, às mesmas normas e legislação, organizados socialmente e governados por entidades que cuidam do bem-estar desse grupo, que se constitui uma sociedade. A palavra vem do Latim societas, que significa "associação amistosa com outros". Sendo assim, toda e qualquer discussão de indivíduo será conseqüentemente uma discussão social.

Todas essas discussões foram feitas, anos e anos pela Psicologia Social que se caracterizava como um ramo da ciência Psicológica que estuda como as pessoas pensam, se influenciam mutuamente e, se interagem entre si. Trata-se de uma ciência mista, responsável tanto pelos fatores psicológicos quanto pelos sociais, sendo que os fatores sociais são 
estritamente para acrescentar as questões sociais ao fator psicológico sendo este último, extremamente individual.

Foi através do olhar da teoria das representações que esse laço entre fator psicológico e social se estreitou. O conceito de representação social teve início com Durkheim (1893) com o conceito da teoria da representação coletiva, onde procurava dar conta de fenômenos como mitos, religião, ciência, e categorias de tempo e espaço, relacionando-as ao conhecimento inerente à sociedade.

No entanto, Moscovici (2014) se afasta desse conceito buscando explicar e compreender a realidade social num contexto, considerando a dimensão histórico-crítica. Desta forma, o conhecimento é adquirido por meio da compreensão alcançada por indivíduos que pensam, porém, não sozinhos, pois a semelhança dos pronunciamentos feitos pelos indivíduos de um grupo demonstra que pensaram juntos sobre os mesmos assuntos.

Assim, o papel dessas representações sociais é averiguar a razão de todas as ideologias coletivas, saberes populares ou senso comum, buscando principalmente uma solução social para essas formas de pensamento.

Isso prova que um indivíduo isolado perde sua racionalidade e que toda forma de pensar é socialmente relevante, ou seja, no mundo das relações entre pessoas tudo é explicado pela interação. Portanto, não existe sociedade sem sujeito e nem sujeito sem sociedade. Assim, esse é o real papel dessa representação social compartilhada, fazendo com que essas relações coexistam.

Segundo Camila Betoni (2014) a sociologia é a disciplina que se ocupa de estudar a vida social humana, analisando as dinâmicas da sociedade como um todo e dos grupos singulares que a compõem. Contudo, enquanto o indivíduo na sua singularidade é estudado pela psicologia, a sociologia tem uma base teórico-metodológica voltada para o estudo dos fenômenos sociais, tentando explicá-los e analisando os seres humanos em suas relações de interdependência.

No entanto, ainda faltava algo que interligasse o estudo individual a partir de uma esfera social. Em seu livro Representações Sociais: a teoria e sua história, Guareschi (1994) cita que surge no século XX a Psicologia Social, analisada por um ramo da Psicologia que estuda como as pessoas pensam, influenciam e se relacionam uma com as outras, reconhecida na América do Norte por, apenas, mais um ramo da sociologia. Allport (1987) critica essa esfera completamente ligada à tradição ocidental acontecendo em uma era moderna. Diante dos fatos, 
esses novos olhares influenciam uma Psicologia Social sendo enraizada mais na Psicologia que na Sociologia, como dantes acontecia. Em decorrência, resultou num maior número de psicólogos escrevendo sobre o assunto do que os sociólogos.

No entanto, essas denominações não eram vistas em conformidade nos tempos remotos. Para alguns estudiosos mais aprofundados em objetos de estudo, como a religião ou a linguagem, dentre eles Wundt (1832), afirmavam que os fenômenos sendo coletivos, não podiam, ser estudados a partir de fatores internos. Assim, não podiam ser explicados em termos de indivíduo, uma vez que essa individualidade não poderia criar uma nova linguagem e nem mesmo uma nova religião.

Durkheim (2014) também seguia essa linha de raciocínio, mas diferenciava-se pela sua visão de sociedade e não de cultura. Para ele o indivíduo sofre pressão das representações dominantes na sociedade sendo que, é essa sociedade que pensa ou exprime os sentimentos individuais, onde as representações não são, assim, necessariamente conscientes pelos indivíduos.

Com essas linhas de pesquisa supracitadas era inevitável a ruptura na dependência da sociologia e psicologia. Sendo assim, Moscovici (2014) propõe que se estudassem essas representações sociais partindo de uma nova vertente: a Psicologia Social. Sendo essa mais sociológica do que psicológica.

Anos mais tarde, partindo do pressuposto de uma diferenciação do indivíduo sozinho ou dele em multidão, Le Bom (1931) individualiza essa Psicologia Social. Em sua visão, os líderes realizavam uma espécie de hipnose para persuadir sua massa. No entanto, essa individualização chamou a atenção de Freud (1920) que estreitou a ponte entre cultura e influência social. Em seus experimentos fez uso da hipnose sem contudo, obter êxito. Nesse processo, cria sua própria técnica, a psicanálise, descartando a hipótese e fazendo valer a identificação comum do grupo e do líder.

Mead (1931), também teve sua influência na teoria das representações sociais ao afirmar que a linguagem é uma característica humana, social e, em alguns casos, a única fonte dessas representações coletivas.

Partindo desses teóricos e, conseqüente contribuição formula-se a teoria das representações sociais, enfatizando seu conceito de representações coletivas. No entanto, parte seu estudo de sociedades menos complexas. Sendo assim, essa teoria estabelece um limite entre a sociologia e a psicologia. 


\section{Representações Sociais e Formação Docente}

Em seu artigo intitulado As representações sociais e o inconsciente coletivo: um diálogo entre duas linhas teóricas, Marilza Mestre e Rita de Cássia Pinotti (2004) buscaram esclarecer alguns conceitos a luz de Carl Jung para entendermos melhor as idéias precursoras de Moscovici. Carl Jung, psiquiatra suíço nascido em 26 de julho de 1875, deu uma atenção especial para a psicologia voltada para uma função social. Para ele, compartilhamos entre aqueles da nossa mesma espécie, sentimentos e pensamentos advindos de um inconsciente coletivo. Esse inconsciente coletivo na opinião do autor é um conjunto de sentimentos, pensamentos e lembranças compartilhadas por toda a humanidade e que, consequentemente são herdados. (Jung, 1964). Esse conjunto de imagens herdadas é chamado de arquétipos, sendo universais e presentes em todos os indivíduos.

Uma vez que a teoria das representações sociais constitui-se numa teoria sobre a construção dos saberes sociais. É um conjunto de todos os aspectos que permeiam a vida de um sujeito, incluindo-se aí, o momento histórico-cultural em que o sujeito encontra-se inserido, de certa forma, são formadores das representações sociais que este formulará a respeito dos acontecimentos sociais que fazem parte do seu contexto.

Tanto para Jung (1875), como para Moscovici (2014), representar um objeto era tornálo mais familiar ou em conformidade com a totalidade do grupo. Assim, busca mostrar uma realidade, um fenômeno que existe, do qual muitas vezes não nos damos conta, mas que possui grande poder explicativo, que nada mais é que esse inconsciente coletivo de uma sociedade menos complexa.

$\mathrm{Na}$ teoria das representações sociais há duas formas de conhecimento na sociedade contemporânea: retificado e consensual. O primeiro é o saber acadêmico e o segundo, o senso comum. No entanto, na segunda forma de conhecimento, se permeia o inconsciente coletivo com seu conceito de lendas populares, contos de fadas, mitos e religião.

Apreender a representação social de professores, sobre um dado objeto, não é simplesmente registrar as experiências, mas sim compreender como tais experiências integram os contextos psicossociais impregnados de valores, estigmas, crenças na qual orientam os comportamentos e as comunicações. As representações sociais são estratégias desenvolvidas por atores sociais para enfrentar a diversidade e a mobilidade de um mundo que, embora pertença a todos, transcende a cada um, individualmente (JOVCHELOVITCH, 2000). 
A construção dos saberes sociais que envolvem a vida do professor, inclusive o momento e o espaço histórico-cultural em que está inserido bem como o seu cotidiano, e também, como a escola os estabelece, referenciam a teoria das representações sociais a perspectiva do "ser professor", permitindo que ele seja afetado na sua construção de representação social, no que tange a valores e atitudes.

Abordam, também, os processos de produção de sentidos de objetos de interesse da educação, suas relações com a cultura, suas implicações nas práticas dos agentes educativos e sua contribuição para a construção de identidade. As representações estão necessariamente relacionadas às práticas cotidianas e as identidades pessoais e culturais. Contudo, numa postura que visa a efetividade, os programas de formação propiciariam ao educador participar ativa e criticamente no processo de construção de conhecimentos. Portanto, longe de ser um receptáculo de informações a ser reproduzido posteriormente, o professor define-se como autor neste processo: pela ação dos valores, crenças, regras e tradições que marcam suas pertenças e referências, filtra o que lhe chega, fragmentando e deslocando a novidade de modo a dominála e, assim, articulá-la ao que já traz consigo, em termos de conhecimentos de diferentes ordens (MOSCOVICI, 2003; MADEIRA, 2005).

A formação não se constrói por acumulação seja de cursos, conhecimentos ou técnicas, mas sim através de um trabalho de refletividade críticas sobre as práticas e de (re) construção permanente de uma identidade pessoal. Por isso é tão importante investir na pessoa e dar um estatuto ao saber da experiência (NÓVOA, 1991, p.23).

\section{Método}

Para realizar este estudo e atingir o objetivo proposto, fez-se da Pesquisa Qualitativa, por ser um método de investigação científica que foca nas particularidades e experiências individuais. Sendo assim, os entrevistados ficam mais livres para discorrer os seus pontos de vista sobre aqueles assuntos relacionados com o objeto de estudo. Pretendemos então, ter uma compreensão mais ampla da perspectiva dos professores da Escola Estadual Manoel Bandeira, referente à formação continuada através das interpretações desses.

A principal característica da abordagem escolhida - pesquisa qualitativa - é o fator de envolver uma abordagem interpretativa do cotidiano, o que significa estudar as coisas em seus 
cenários naturais, buscando entender os significados que as pessoas a eles, conferem. Seguindo essa premissa, Vieira e Zouain (2005) afirmam ser a pesquisa qualitativa de grande importância, por valorizar as falas e os depoimentos dos atores sociais participantes, bem como os discursos e significados transmitidos por eles. Nesse sentido, tal pesquisa preza por uma descrição detalhada dos fenômenos e dos elementos que os envolvem.

No âmbito dessa pesquisa, ao iniciar o estudo iniciar para a dissertação, a pesquisadora se encontra inserida no campo escolar, na condição de tutora. Desta forma, o olhar da mesma perpassa pelas lentes condicionantes de tutoria.

Quanto a isso, Alves-Mazzotti \& Gewandsznajder (2000) informam que nos estudos qualitativos, a coleta sistemática de dados deve ser precedida por uma imersão do pesquisador no contexto a ser estudado. Nesse caso, em específico, a imersão no campo se deu na condição de tutora de abril a agosto de 2017.

Ao repensarmos um tema do interesse de muitos educadores, procuram contribuir minimamente para tentar solucionar uma das muitas dificuldades que identificamos durante o estudo. Objetivou-se compreender o processo de construção de um projeto de formação continuada de uma escola pública e seu desenvolvimento, bem como suas relações com as representações sociais. Para analisar essa prática no ambiente escolar, optou-se pela análise de um grupo de professores, visto que a formação nessa escola acontece em dois turnos diversificados, assim como também, documentos que oriente teoricamente, sob o olhar de autores como Falsarella (2004), Freitas (2007), Perrenoud (2000), Nóvoa (1991), Freire (1991), Luckesi (1994), Libâneo (2005), Guareschi (1994), Moscovici (1978) e Jodelet (2002), além de entrevista com os professores e pesquisa in loco.

A matriz histórica que nos forneceu subsídios para a descrição do contexto local da pesquisa foi delineado através de entrevista aberta.

\section{Resultados}

Essa pesquisa foi realizada com 12 (doze) profissionais da educação que compunham um grupo de estudo no período vespertino. Desses, três eram técnicos administrativos que participaram de alguns encontros e posteriormente foram selecionados para novas temáticas que contemplassem seus trabalhos na secretaria da escola. Quatro professores pedagogos, um 
geógrafo, um biólogo, um historiador, um matemático e uma estudante de direito que ocupa o cargo de auxiliar de turma. Foi realizado levantamento de quanto tempo esses professores lecionavam na educação e quanto tempo nessa instituição de ensino. A análise está exposta abaixo.

Tabela 1 - Profissionais da educação que compunham um grupo de estudo no período vespertino.

\begin{tabular}{l|l|l}
\hline \multicolumn{1}{c|}{ Professor } & \multicolumn{1}{c|}{ Tempo na educação } & \multicolumn{1}{c}{$\begin{array}{c}\text { Tempo na instituição } \\
\text { analisada }\end{array}$} \\
\hline \hline Pedagogo 1 & 25 anos & 5 anos \\
\hline Técnico administrativo 1 & 5 anos & 10 meses \\
\hline Historiadora & 15 anos & 6 anos \\
\hline Pedagogo 2 & 20 anos & 9 anos \\
\hline Matemático & 14 anos & 8 meses \\
\hline Técnico administrativo 2 & 25 anos & 19 anos \\
\hline Técnico administrativo 3 & 7 meses & 7 meses \\
\hline Pedagoga 3 & 17 anos & 5 anos \\
\hline Auxiliar de turma & 1 ano & 8 meses \\
\hline Bióloga & 19 anos & 3 anos \\
\hline Geógrafa & 10 anos & 1 ano e 6 meses \\
\hline Pedagoga 4 & 17 anos & 12 anos \\
\hline \hline
\end{tabular}

Fonte: autor.

\section{A Identidade Profissional do Professor}

Segundo Vygotsky (1978), que o indivíduo é sempre uma entidade social e, consequentemente, um símbolo vivo do grupo que ele representa. [...] O indivíduo no grupo como o grupo no indivíduo - contanto que tenhamos uma compreensão adequada do contexto social por ele habitado (cf. p.123 e 124). Evidenciamos assim que as práticas docentes dos professores fazem parte da identidade de uma escola, pois constatou que a maioria dos profissionais está na mesma instituição entre 8 meses e 19 anos. 
Podendo-se caracterizar essa identidade como fruto de memórias coletivas, constituindo assim, um produto histórico-crítico. Além disso, é importante frisar que uma identidade profissional é influenciada por diversos fatores dentre eles os que merecem destaque são os sociológicos, psicológicos, cognitivos e culturais. É preciso compreender que ela não é fixa, e sim construída através de atividades relacionais. Que evolui e se desenvolve tanto pessoal quanto coletivamente. Não é algo que se possui e sim algo que se desenvolve durante toda uma vida.

Envolve tanto o sujeito, como o cenário. Não é singular. Espera-se que os professores se comportem de maneira profissional, mas não porque adotem conhecimentos e atitudes prescritas. Diferenciam entre si em função da importância que dão a esses conhecimentos e atitudes e, desenvolvendo sua própria resposta ao contexto.

Portanto, perceberam-se que a identidade profissional dos colaboradores foi também permeada pela filosofia e ideal da escola e, também pelas identidades dos demais profissionais envolvidos no trabalho docente da instituição de ensino. Isso fica bem claro na conversa com o profissional que trabalha há muito tempo na escola sobre a permanência dos profissionais por um longo tempo no mesmo estabelecimento de ensino, a professor 1 relata que:

Quando o professor já está no grupo há mais tempo fica mais fácil dele trabalhar, pois já conhece as regras da escola e como nós costumamos trabalhar aqui. Não precisamos ficar tudo de novo? (Professora 1)

No entanto a professora 2 afirma que

o professor novo dá uma injeção de ânimo nos demais e também é interessante que todo ano as regras ou regimento sejam passados para todos. Os novos vão conhecer e os antigos vão relembrar. (Professora 2)

Na perspectiva de Lasky, essa identidade profissional é a maneira como os professores vêem a si mesmos e aos outros. É uma composição do "si mesmo" que prospera ao longo da carreira docente e que pode achar-se influenciado pela instituição que leciona, pelas reformas e pelas políticas públicas, que "inclui o compromisso pessoal, a disposição para aprender a ensinar, as crenças, os valores, o conhecimento sobre a matéria que ensinam, assim como sobre o ensino, as experiências passadas, assim como a vulnerabilidade profissional" (Lasky, 2005). As identidades profissionais formam uma "complexa rede de histórias, conhecimentos, processos e rituais" (Sloan, 2006). 
Mas essa complexa rede de histórias está permeada por desafios como a rotatividade de profissionais e assim passam a ser evidências em relação ao fato de que as mudanças nas condições internas e externas das escolas produziram condições de extrema incerteza e crise de identidade dentro do que historicamente foi, para muitos professores, uma profissão estável (Day, Elliot, \& Kington, 2005).

\section{A Feminização do Magistério}

Verificou-se que a maioria dos profissionais da educação participantes é do sexo feminino. De acordo com dados divulgados pelo MEC (Ministério da Educação) no fim de 2010, existiam quase 2 milhões de professores, dos quais 1,6 são do sexo feminino. Em uma entrevista para a redação do Todos pela Educação (2011) a socióloga Magda de Almeida Neves, da PUC - Minas (Pontifícia Universidade Católica de Minas Gerais) afirma que esse percentual pode ser explicado historicamente. Segundo ela, a sociedade brasileira associa a função do professor a características geralmente consideradas femininas, como a atenção, a delicadeza e a meiguice.

Ainda referenciando a socióloga acima citada, "esses predicados são comumente associados aos de uma mãe e, para possuí-los não é necessário qualificação profissional. Com isso, os salários do magistério podem ter sofrido impactos, se desvalorizando frente a outras profissões e fazendo com que a Educação permaneça como um "gueto feminino no mercado de trabalho".

Entretanto, essas representações sociais da mulher refletem experiências autoritárias e subordinativas, nas quais se estruturam inibindo a participação social da mulher nos fatos de sua vida cotidiana. Para Sirvent (1984) a imagem feminina é inibitória do reconhecimento das necessidades de participação, reflexão, criação, auto-valorização e valorização de qualquer conduta que modificará a conduta da rotina doméstica feminina: a mulher é percebida só como mulher na casa, atendendo aos afazeres domésticos, aos filhos e ao marido (pág. 155).

Ao ser questionada sobre sua escolha profissional, uma das pedagogas salientou:

Na minha família todas as mulheres são professoras, minha mãe era professora de ciências, minha avó de geografia. Minha avó contava que na época dela sempre quis que ela pudesse ensinar e cuidar das crianças. (Professora 3) 
Podemos observar que a referência de profissional docente foi remetida ao afeto maternal, a relação professor e aluno estreitam-se num laço fraternal e configurando-se uma imagem de professor doutrinador. Nesse aspecto a função caracteriza-se com mais preocupação na educação moral do que no processo de ensino-aprendizagem. Alguns ainda assimilam a função docente á tia. Paulo Freire afirma

\begin{abstract}
“(...) Professora, porém, é professora. Tia é tia. É possível ser tia sem amar seus sobrinhos, sem gostar sequer de ser tia, mas não é possível ser professora sem amar os alunos - mesmo que amar, só, não baste - e sem gostar do que se faz. (...) Não é possível também ser professora sem lutar por seus direitos para que seus deveres possam ser melhor cumpridos. Mas, você, que está me lendo agora, tem todo o direito de, sendo ou pretendendo ser professora, querer ser chamada de tia ou continuar a ser. Não pode, porém, é desconhecer as implicações escondidas na manha ideológica que envolve a redução da condição de professora à de tia" (p.26, "Professora sim, Tia não", 2005).
\end{abstract}

Esse afeto fica comprovado na fala da Professora 3

Alguns dos meus alunos só recebem meus carinhos na escola, muitos passam mais horas comigo do que com os próprios pais. (Professora 3)

\title{
Relações Raciais no Contexto Escolar
}

Podemos avaliar que além do embate da profissão vista como feminina, constata-se também o grupo apresenta somente um profissional negro. Este único profissional ocupa o cargo/função de auxiliar de turma, sendo exigida escolaridade do Ensino Médio para exercê-la, recebendo remuneração condizente a escolaridade. Cabe aqui a observação que o mesmo cursa Direito em uma Universidade Estadual no município. Vale ressaltar que se trata de uma auxiliar contratada temporariamente destinado a escola que apresentam alunos com alguma deficiência para possibilitar o processo de inclusão.

Refletindo esse contexto, cabe aqui o filme brasileiro intitulado "Quanto Vale ou É por Quilo?”, dirigido por Sérgio Bianchi em 2005, onde o autor faz uma analogia entre o antigo comércio de escravos e a atual situação social. Através de cenas de caráter histórico Sérgio Bianchi contrasta a posição social do negro na sociedade brasileira levando-nos a uma reflexão sobre o papel de cada cidadão na sociedade capitalista seguida por sua discriminação de 
raça/cor. Reforça que todos têm a chance de participar nas questões políticas e econômicas do Estado, mas como se observa no filme, os menos privilegiados não têm direito algum em nossa sociedade. Ora, atualmente, vivemos em uma sociedade onde só os mais fortes (e ricos) lideram o poder.

Contudo, essa relação educação, sociedade, raça e cultura vêm configuradas nas palavras a seguir:

\begin{abstract}
A marca da sociedade e da cultura dominante é impressa em uma variedade de práticas escolares, isto é, na linguagem oficial, nas regras da escola, nas relações sociais na sala de aula. É desnecessária dizer que ela não é simplesmente impressa ou imposta sobre a consciência ou sobre as ideologias dos oprimidos. É crucial reconhecer que as escolas representam terrenos contestados na formação das subjetividades, mas que esse terreno é tendencioso a favor da cultura dominante. (GIROUX, 1986, p. 94-95)
\end{abstract}

Ao ser questionado sobre a razão de se ter a maioria dos profissionais autodenominados brancos a professora negra diz:

Nunca observei que somos em poucos na escola. Mas vou pensar nisso a partir de agora. Sempre me senti acolhida nessa escola e nunca passei por nenhuma situação que pudesse me deixar constrangida. (Professora 4)

Percebemos através deste que como afirma Jaques (2008) a representação social trata desses saberes produzidos pela sociedade, e que são capazes de gerar marcas positivas ou não em um determinado grupo e que afetam a forma como as mesmas percebem a si próprias. A professora afirma nunca ter vivenciado nenhum tipo de preconceito no seu grupo, no entanto esse fator não pode ser estendido para todo o restante da sociedade.

A escola conta com um profissional especializado em Relações Raciais no Contexto da Educação de Jovens e Adultos - EJA que participou da pesquisa e quando indagada pela mesma questão anterior relatou:

Os negros vêm sendo excluídos há muito tempo, só o fato de trazê-los para trabalhar em um país nas condições que vieram já remete o pior tipo de exclusão. (Professora 5)

Para Bourdieu (2007), as representações sociais são sempre determinadas pelos interesses dos grupos que as forjam. Assim não seriam discursos neutros, pois tenderiam a impor determinada visão de mundo, que implicaria em condutas e escolhas. A representação 
que os indivíduos e os grupos exibem inevitavelmente através de suas práticas e propriedades faz parte integrante de sua realidade social. (p.447).

Bourdieu também nos auxilia a entender as particularidades das representações feitas através da ideologia do branqueamento sobre o "negro" através da concepção de "violência simbólica", ou a autoridade de um determinado grupo sobre outro por meio de símbolos e de palavras. Para ele, essa violência impõe acepções como sendo verdades absolutas, “[...] dissimulando as relações de força que estão na base de sua força, acrescenta sua própria força, isto é, propriamente simbólica a essas relações de força”. (BOURDIEU, 2007b, p. 25).

Ainda na sua fala a professora esclarece

Poucos conseguiam entrar nas licenciaturas antes das cotas e agora que temos as cotas poucos conseguem permanecer. Elas garantem a entrada, mas não a permanência. Em uma pesquisa que participei comprovamos que os alunos que ingressam na faculdade federal de Mato Grosso sofrem diversos preconceitos em sala de aula: os colegas de sala excluem por terem ingressado e a própria faculdade não gosta da presença deles. E mediante esse contexto muitos acabam desistindo (Professora 5).

Podemos assim analisar nesse trecho a forte influência de uma violência simbólica sofrida todos os dias por profissionais da educação ou de outros setores. A professora complementa,

\begin{abstract}
Mas respondendo a sua pergunta o principal fator que nos revela a não existência de muitos negros lecionando nas escolas é o ingresso tardio dos mesmos nas licenciaturas. Mas acredito que o problema não seja somente a presença dos professores negros em sala de aula e sim a frequiência de situações desagradáveis que já vivenciei. Meu filho estudava em uma escola particular e conta que sua professora pediu para abrirem o livro na página em que havia um macaco (homem negro) em cima de um cavalo. E complementa que uma de suas colegas optou por mudar de cidade devido às situações desconcertantes que passava na cidade devido a sua cor. (Professora 5)
\end{abstract}

Desta forma fica claro como nossas representações sociais são permeadas de fatores históricos. Sendo assim essa representação do negro não se explica sozinha, mas sim por uma sociedade que as fundamenta e cria. 


\title{
A Representação Social da Formação Continuada
}

O maior anseio desse grupo sempre foi que a formação continuada pudesse auxiliar a prática pedagógica e aumentasse o interesse dos alunos pelas atividades escolares. Sendo assim, a cada encontro haveria uma transposição didática que permitisse fazer relações ente teoria e prática. Quando questionada sobre a formação continuada da escola a professora relata

\begin{abstract}
No início fiquei feliz por que parece que estávamos escolhendo nosso caminho para os estudos. $\mathrm{O}$ ano passado o governo mandou os projetos prontos e não aproveitamos muito. Este ano escolhemos o tema, separamos os textos para leitura e montamos o projeto. Mas não sei por onde se perdeu, pois chegou o final do ano o aproveitamento não foi o que eu esperava. (Professor 6)
\end{abstract}

Percebe-se que a professora caracteriza a imagem de formação continuada como condutora do futuro e anseia que o tempo de estudo destinado á formação deva suprir as necessidades da sala de aula e possibilitar uma reflexão acerca de suas práticas. Assim também para Garcia (1999) a proposta de capacitação docente deve estar relacionada às necessidades específicas de ensino e á aquisição de competências necessárias para o desenvolvimento da atividade docente. (p.47)

De acordo com a análise feita por Candau (1997), os cursos de formação continuada, apoiados em idéias de aperfeiçoamento e capacitação, pouco se aproximam das necessidades reais dos professores que estão atuando no chão das escolas públicas deste país. (P. ) isso fica bem explícito na entrevista da professora 7

\begin{abstract}
Mesmo escolhendo nossos temas quando voltávamos para nossa sala de aula não conseguíamos utilizar a grande maioria deles. Ao fazer a transposição didática essa ponte se estreitou e até facilitou essa práxis, mas não víamos essa luz no fim do túnel em todos os textos. Eram leitura e mais leituras só. E quando íamos falar de avaliação escolar o governo implantou um novo programa - AVALIA/MT - acabamos tendo que nos voltar a essa nova política.
\end{abstract}

Ao identificar a dificuldade de concluir o projeto da formação continuada da escola, a professora deixa claro a angústia por eles vividos. Assim conforme relata Day, Elliott e Kington, "os professores estão deixando de lado o que consideram parte essencial de seu trabalho, a interação com os alunos, para abordar as prioridades de gestão e de avaliação" (Day, Elliot, \& Kington, 2005). 
Questionada sobre qual o real papel da formação continuada, outra professora explana que "a formação precisa proporcionar momentos de socialização de experiências. (Professor 7)"

Nesses momentos de socialização acontecem as reflexões da prática pedagógica. Para Freire (2006) essa reflexão crítica sobre a prática é o principal momento da formação dos professores. (P. 39)

\begin{abstract}
Quando ingressamos na carreira docente somos alimentados de anseios para uma educação transformadora, almejamos aplicar toda a prática de ensino adquirida no período acadêmico, no entanto, quando nos deparamos com a realidade profissional, encontramos um mundo desafiador de educar intelectualmente pessoas com todos os tipos de personalidade e a minha esperança era que a formação continuada pudesse auxiliar ou amenizar esses problemas, mas isso está longe de acontecer. (Professor 8)
\end{abstract}

Podemos perceber então que além dos professores apresentarem ideologias sobre a formação continuada também buscam novos caminhos nessa ideologia. Esperam que a formação possa lhes dar suporte intelectual e nortear consideravelmente os trabalhos e angústias do dia-a-dia. Criam uma expectativa que poderia ser amenizada nas socializações das próprias experiências do grupo se essas fossem valorizadas.

Em um desabafo, uma das técnicas administrativas questiona sobre a escolha do tema da formação continuada:

O que vamos melhorar na nossa escola estudando todos esses textos? Quem escolheu esses textos? Precisamos aprender a fazer aulas diferentes para nossos alunos aprenderem? [Técnica 1].

Nota-se o anseio por uma formação mais prática e que as teorias possam vir ao encontro dos problemas enfrentados na realidade escolar. Podemos perceber que a concepção da técnica muito se assemelha ao que Shulman(1998) denomina de profissão docente sendo caracterizada como uma comunidade de prática através da qual "a experiência individual possa se converter em coletiva” (p. 521)

Observam-se também em alguns momentos, visões de profissionais desamparados, onde um dos docentes diz estar cansado de andar sozinho. Portanto, denota-se na formação dessa imagem, consideração de "desamparados", "pobrezinhos", como tendo "vocação desvalorizada", trabalhando em instituições com condições insatisfatórias para o exercício adequado da profissão. 


\section{Considerações Finais}

Ao estudar as representações sociais a luz da formação continuada em uma escola estadual de Alta Floresta, trazemos uma reflexão de como essas representações sociais interferem diretamente na nossa prática. Atualmente diversas tem sido as discussões sobre as práticas pedagógicas adotadas na escola, principalmente quando enfatiza a formação do professor e as tendências que influenciam diretamente seu trabalho. À medida que certas discussões educacionais são elencadas, ressalta-se também algumas situações interdisciplinares da educação contudo, na era da tecnologia/informação, o profissional da educação necessita a todo instante fazer uma reflexão de sua prática pedagógica para que haja mudança estrutural e conceitual.

Precisamos compreender que a prática educativa não é um acontecimento isolado de seu contexto sócio-cultural, mas uma construção social inserida no contexto escolar que, por sua vez, precisa estar intimamente ligada à formação cidadã e, conseqüentemente, vinculada a uma representação social. Além disso, é importante pontuar que a identidade é construída sob a influência de diversos fatores, dentre os quais, os fatores sociológicos, psicológicos, cognitivos e culturais.

Através da presente pesquisa pode-se observar que as representações fazem parte do cotidiano escolar e da formação da identidade profissional, mesmo sem ser percebida. Notouse que, a imagem que o professor tem de si, também reflete no seu trabalho profissional e nas suas expectativas quanto à formação continuada. Assim, verificou-se que o sentido de identidade identitário produzido pelo professor, reflete indubitavelmente em sua conduta no espaço escolar.

Percebeu-se, mediante essa análise, que a construção da identidade do professor é um processo que está diretamente ligado ao contexto sócio-cultural no qual ele está inserido. E essa aproximação com a realidade específica nos fez analisar que a construção da identidade correlaciona-se a um contexto que vai além de espaços da vida cotidiana.

Também se torna relevante atentar para outro aspecto na formação da identidade profissional, a imagem feminina. Todos os profissionais envolvidos na pesquisa são mulheres, recordando as Escolas Normalistas, denotando que ainda temos uma sociedade arraigada na concepção da profissão correlaciona com a imagem de professores como moças bem educadas, sofisticadas e delicadas. 
Ressalta-se ainda, a situação étnico-racial. Esse contexto se torna problemático partindo do viés de um sujeito destinado a um lugar marginalizado e ausência de políticas de seguridade social. E, mais freqüentemente em um plano simbólico, onde o negro é representado socialmente com qualidades negativas e desqualificadas.

Para se construir qualquer identidade profissional é necessária, primeiramente, compreender e aceitar as diversas facetas que compõem a Identidade Docente. E que essas diversas facetas são inseridas em um contexto que, ora há socialização e ora rejeição, mudando de contextos a cada instante com o mover da sociedade.

\section{Referências Bibliográficas}

ALVES-MAZZOTTI, Alda Judith; GEWANDSZNAJDER, Fernando. O método nas ciências naturais e sociais: pesquisas quantitativas e qualitativas. São Paulo: Editora Pioneira, $1998\left(1^{\text {a }}\right.$ edição); 1999 ( $2^{\mathrm{a}}$ edição); 2000 ( $1^{\mathrm{a}}$ reimpressão), 2001 ( $2^{\mathrm{a}}$ reimpressão), 2002 ( $3^{\mathrm{a}}$ reimpressão), 2004

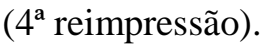

BRASIL. Presidência da República. Lei no 9.394, de 20 de dezembro de 1996. Estabelece as diretrizes e bases da educação nacional. Disponível em: <http://www.planalto.gov.br/ccivil_03/leis/19394.htm>. Acesso em: 01 set. 2013.

COSTA, Marisa Vorraber et al. O Currículo nos Limiares do Contemporâneo. Rio de Janeiro: DP\&A editora, 1999.

DAY, C., ELLIOT, B., e KINGTON, A. Reform, standards and teacher identity: Challenges of sustaining commitment. Teaching and Teacher Education, 2005, 21, 563-577.

FALSARELLA, A. M. Formação continuada e prática de sala de aula: os efeitos da formação continuada na atuação do professor. Campinas: Autores Associados, 2004.

FERRAZ, C. H. A privatização do vocabulário docente. Bacharelado em Psicologia Social. Universidade Federal de Pernambuco. 1993.

FRANCO, Maria Laura Puglisi Barbosa \& VARLOTTA, Yeda Maria da Costa. As Representações Sociais de Professores do Ensino Médio. Estudos em Avaliação Educacional, v.15, n.30, p. 17 a 28. Jul-dez/2004,

GIROUX, H. Teoria Crítica e política cultural: para além das teorias de reprodução. Petrópolis: Vozes, 1986.

JACQUES. Maria da Graça Corrêa (et al.). Psicologia Social Contemporânea: livro-texto. 11. ed. Petrópolis, RJ: Vozes, 2008. 
JODELET, D. (Org.). Representações sociais: um domínio em expansão. In: JODELET, D. As Representações Sociais. RJ: EdUERJ, 2001, p. 17-44.GODOY, A. S. Refletindo sobre critérios de qualidade da pesquisa qualitativa. Revista Eletrônica de Gestão Organizacional, v. 3, n. 2, p. 81-89, mai./ago. 2005.

JoVcHeloVitcH, s. Vivendo a vida com os outros: intersubjetividade, espaço público e representações sociais. in: gUarescHi, p.; JoVcHeloVitcH, s. (orgs.). Textos em representações sociais. petrópolis: Vozes, 2011. p. 53-721

LIBÂNEO, José Carlos. Democratização da Escola Pública. São Paulo : Loyola, 1990.

LIBÂNEO, José Carlos. Educação escolar: políticas, estrutura e organização. São Paulo: Cortez, 2005.

LUDKE, M. e ANDRÉ, M. E. D. A. Pesquisa em educação: abordagens qualitativas. São Paulo: EPU, 1986.

MATO GROSSO, Secretaria de Educação e Cultura. Parecer orientativo/2011 Projeto Sala de Educador. Superintendência de Formação dos Profissionais da Educação Básica. Cuiabá: Seduc, 2011.

MINISTÉRIO DA EDUCAÇÃO. Lei no 9.394/1996, que estabelece as Diretrizes e Bases da Educação. Brasília: MEC, 1996.

MINISTÉRIO DA EDUCAÇÃO. Decreto no 6.755/2009,que institui a Política Nacional de Formação dos Profissionais do Magistério de Educação Básica. Brasília: MEC, 2009.

MINISTÉRIO DA EDUCAÇÃO. Lei no 10.172/2001,que estabelece o Plano Nacional de Educação. Brasília: MEC, 2001.

NÓVOA, Antônio (1992 a). Formação de professores e profissão docente. In: NÓVOA (org) Os professores e a sua formação. Lisboa: Publicações Dom Quixote.

NÓVOA, A. Para o estudo sócio-histórico da gênese e desenvolvimento da profissão docente. Teoria \& Educação. 1991, no 4, p. 109-139.

PROJETO SALA DE EDUCADOR. SUFP/SEDUC/MT. Cuiabá, 2011b.BRASIL. Ministério da Educação. Plano decenal educação para todos. Brasília: MEC, 1993.Secretaria de Educação e Cultura. Política de formação dos profissionais da educação básica de Mato Grosso.Cuiabá: SEDUC, 2010.

RICHARDSON, R. J. Pesquisa social: métodos e técnicas. São Paulo: Atlas, 1999.

RICHTER, Marcos Gustavo. Ensino do Português e Interatividade. Santa Maria : Editora da UFSM, 2000.

ROUSSEAU, J.-J. As confissões. v. 2. Trad. Rachel de Queiroz. 2 ed. São Paulo: Atena, 1959.

SIRVENT, Maria Teresa. Educação Comunitária: experiência do Espírito Santo. São Paulo: Editora Brasiliense s.a. 1984.

SHULMAN, L. (1998). Theory, Practice, and the Education of Professional. The Elementary School Journal, 98(5), 511-526.

SLOAN, K. (2006). Teacher identity and agency in school worlds: beyond the all-good/all-bad discourse on accountability-explicit curriculum policies. Curriculum Inquiry, 36(2), 119-152. 
VIEIRA, M. M. F. e ZOUAIN, D. M. Pesquisa qualitativa em administração: teoria e prática. Rio de Janeiro: Editora FGV, 2005.

VYGOTSKY, L. S. (1978). Interaction between learning and development (M. Lopez-Morillas, Trans.). In M. Cole, V. John-Steiner, S. Scribner, e E. Souberman (Eds.), Mind in society: The development of higher psychological processes (pp. 79-91). Cambridge, MA: Harvard University Press.

\section{Como citar este artigo (Formato ABNT):}

BACK, Giselle Pupim J. Representação Social e Formação Continuada dos Professores da Educação Básica da Escola Estadual Manoel Bandeira. Id on Line Rev.Mult. Psic., 2018, vol.12, n.40, p.116137. ISSN: 1981-1179.

Recebido: $17 / 02 / 2018$

Aceito 20/02/2018 